\title{
The effect of epidural administration of dexamethasone on postoperative pain: a randomized controlled study in radical subtotal gastrectomy
}

\author{
Youn Yi Jo ${ }^{1}$, Ji Hyun $\mathrm{Yoo}^{2}$, Hyun Joo Kim², and Hae Keum Kil ${ }^{2,3}$ \\ ${ }^{1}$ Department of Anesthesiology and Pain Medicine, Gachon University of Medicine and Science Gil Medical Center, Incheon, \\ ${ }^{2}$ Department of Anesthesiology and Pain Medicine, ${ }^{3}$ Anesthesia and Pain Research Institute, Yonsei University College of Medicine, \\ Seoul, Korea
}

Background: Epidurally administered dexamethasone may reduce the incidence and severity of postoperative pain. We investigated whether postoperative pain could be alleviated by preoperative or postoperative epidural dexamethasone administration in patients undergoing major abdominal surgery.

Methods: Ninety patients (age 30-77 with American Society of Anesthesiologists physical status I and II) undergoing radical subtotal gastrectomy were randomly allocated to three groups using computer generated randomization. In all groups, $10 \mathrm{ml}$ of $0.25 \%$ ropivacaine was injected epidurally before the start and at the end of the operation. In Group I, a bolus ropivacaine epidural without dexamethasone was administered. In Group II, dexamethasone ( $5 \mathrm{mg}$ ) was added to the ropivacaine bolus epidural before the start of operation. In Group III, the same amount of dexamethasone was given with the ropivacaine epidural at the end of operation. Effort and resting VAS, the use of rescue analgesics and any complications noted during the procedure were evaluated.

Results: VAS and requirements of rescue analgesics were significantly lower in Groups II and III when compared to Group I. There were no difference in the incidence of nausea and vomiting between groups, but an itching sensation was frequent in Group III.

Conclusions: The administration of $5 \mathrm{mg}$ of dexamethasone epidurallly, before or after operation, could reduce the pain and analgesic requirement after radical subtotal gastrectomy. (Korean J Anesthesiol 2011; 61: 233-237)

Key Words: Dexamethasone, Epidural, Gastrectomy.

Received: December 29, 2010. Revised: 1st, January 28, 2011; 2nd, Feburary 23, 2011. Accepted: March 3, 2011.

Corresponding author: Hae Keum Kil, M.D., Department of Anesthesiology and Pain Medicine, Anesthesia and Pain Research Institute, Yonsei University College of Medicine, 250, Seongsan-no, Seodaemun-gu, Seoul 120-752, Korea. Tel: 82-2-2228-2414, Fax: 82-2-2228-7897, E-mail: hkkil@yuhs.ac

(c) This is an open-access article distributed under the terms of the Creative Commons Attribution Non-Commercial License (http:// creativecommons.org/licenses/by-nc/3.0/), which permits unrestricted non-commercial use, distribution, and reproduction in any medium, provided the original work is properly cited. 


\section{Introduction}

Adequate postoperative pain control can improve postoperative recovery and reduce morbidity.

Several adjuvants have been used to enhance analgesia and prolong the analgesic duration, as well as reduce opioid requirements and related side effects.

Corticosteroids have a powerful anti-inflammatory action and have demonstrated reduced pain and swelling after various surgeries, but the exact mechanism of the analgesic effect is not fully understood $[1,2]$. Steroids are also known to inhibit phospholipase $\mathrm{A}_{2}$ and the expression of cyclooxygenase-2 during inflammation. Thus, reduced prostaglandin synthesis suppresses hyperalgesia associated with acute nociception during surgery [3]. Although steroids given epidurally were effective in the treatment of lower back pain [4], in addition to reducing postoperative pain and analgesic requirements [5], the potential efficacy of postoperative analgesia has not been elucidated.

This study was designed to investigate whether postoperative pain could be alleviated by epidural administration of dexamethasone in patients undergoing major abdominal surgery.

\section{Materials and Methods}

This randomized controlled study was approved by the institutional review board and written informed consent was obtained from all study participants. Ninety patients (age 3077 and having American Society of Anesthesiologists physical status I and II) scheduled for radical subtotal gastrectomy due to stomach cancer by a single surgeon were included to this study from June 2009 to July 2010. Patients with a history of cardiac, respiratory, neuromuscular, hepatic or major renal disease were excluded from this study. Patients were also excluded if they were obese, diabetic, had local infection, spinal anomalies, infectious diseases, neurologic disorders, seizures and coagulopathies or if they were receiving analgesics, corticosteroids or calcium channel blocking drugs.

Using computer generated randomization, patients were allocated to three groups: Group I $(n=30$, local anesthetics only), Group II ( $\mathrm{n}=30$, epidural dexamethasone, $5 \mathrm{mg}$ prior to surgery), and Group III ( $\mathrm{n}=30$, epidural dexamethasone, $5 \mathrm{mg}$ at the end of surgery). The patient and the investigator involved in the data collection were not aware of the patient group assignment/treatment. All drugs used for epidural injection ( $0.25 \%$ ropivacaine with $5 \mathrm{mg}$ dexamethasone or same volume of saline) were prepared in the anesthesia preparation room by a nurse who was blinded to the study. Anesthetic practitioners, who were also blinded to the group allocation, managed the anesthesia.
On arrival to the operating room, standard monitors were applied to the patients. Epidural paramedian puncture was performed at the T7-8 interspace with $17 \mathrm{G}$ Touhy needle in the lateral decubitus position. After identifying the epidural space with loss of resistance technique, a $20 \mathrm{G}$ multi-orifice epidural catheter was threaded and advanced $6 \mathrm{~cm}$ cephalad and safely fixed. Successful epidural catheterization was confirmed with sensory changes after a test dose of $2 \%$ lidocaine ( $3 \mathrm{ml}$ ) was injected. Anesthesia was induced with propofol and remifentanil infusion. Tracheal intubation was performed after rocuronium administration and anesthesia was maintained with sevoflurane in air $/ \mathrm{O}_{2}\left(\mathrm{FiO}_{2}=0.5\right)$. Supplemental remifentanil was continuously infused. In all groups, $10 \mathrm{ml}$ of $0.25 \%$ ropivacaine was injected epidurally before the start and at the end of the operation. In Group I, epidural ropivacaine without dexamethasone was epidurally administered. In Group II, epidural dexamethasone ( $5 \mathrm{mg}$ ) was added to the bolus ropivacaine injection before the start of operation. In Group III, the same amount of dexamethasone was given with the epidural ropivacaine treatment at the end of operation.

During surgery, the anesthetic depth was maintained within a range of $\pm 20 \%$ from baseline values for heart rate and arterial blood pressure and the bispectral index was maintained within a range of 40-60. Subtotal gastrectomy with gastroduodenostomy (Billoth I) surgery was then initiated. After the second bolus epidural injection, an infusion device (Automed-3200 ${ }^{\circledR}$, Acemedical, Seoul, Korea) prefilled with $0.15 \%$ ropivacaine and $1,000 \mu \mathrm{g}$ of fentanyl with a total volume of $250 \mathrm{ml}$ was connected to the epidural catheter. The infusion device was programmed with a basal infusion rate of $5 \mathrm{ml} / \mathrm{h}$ without an intermittent bolus dose. After the surgery, the residual neuromuscular blockade was reversed with pyridostigmine and glycopyrrolate, and then $4 \mathrm{mg}$ of ondansetrone was given. When the patient responded to verbal commands and neuromuscular function was ascertained by 4 responses of the adductor pollicis to train of four stimulation with sufficient spontaneous respiration determined by tidal volume and respiratory rates, the tracheal tube was removed. In the post-anesthesia care unit (PACU), postoperative pain was assessed using the visual analog scale (VAS) score at rest and with effort (i.e. coughing and at $30^{\circ}$ sitting) at 5 minutes (T1) and 30 minutes (T2) after entry. When the patient requested an analgesic, $50 \mu \mathrm{g}$ of fentanyl was administered i.v. in the PACU. After discharge from the PACU, two nurse investigators blinded to the study groups assessed the pain scores $24 \mathrm{~h}$ (T3) and $48 \mathrm{~h}$ (T4) after surgery. The incidence of adverse effects, such as peripheral oxygen desaturation $\left(\mathrm{SpO}_{2}\right.$ $<90 \%$ ), nausea or vomiting, somnolence, and pruritus (rubbing or scratching the skin) were recorded. Patients were instructed to request analgesics from the nurse when needed. Meperidine (25 mg, i.v.) was given as the rescue analgesic. 
All data were analyzed with PASW Statistics $18^{\circledR}$ (SPSS Inc., Chicago, IL, USA). Continuous variables were shown as mean \pm SD and categorical variables were shown as numbers. A series of one-way ANOVAs were conducted to examine differences

Table 1. Patient Characteristics

\begin{tabular}{lccc}
\hline & $\begin{array}{c}\text { Group I } \\
(\mathrm{n}=30)\end{array}$ & $\begin{array}{c}\text { Group II } \\
(\mathrm{n}=30)\end{array}$ & $\begin{array}{c}\text { Group III } \\
(\mathrm{n}=30)\end{array}$ \\
\hline Age (yr) & $56 \pm 10$ & $58 \pm 12$ & $57 \pm 9$ \\
Sex (M/F) & $22 / 8$ & $22 / 8$ & $20 / 10$ \\
Weight (kg) & $63 \pm 8$ & $61 \pm 10$ & $63 \pm 9$ \\
Height (cm) & $167 \pm 7$ & $165 \pm 7$ & $164 \pm 6$ \\
Operation time (min) & $196 \pm 58$ & $175 \pm 60$ & $185 \pm 58$ \\
Anesthesia time (min) & $225 \pm 63$ & $205 \pm 55$ & $222 \pm 56$ \\
Intake fluid (ml) & $1,289 \pm 500$ & $1,363 \pm 595$ & $1,274 \pm 410$ \\
Urine output (ml) & $266 \pm 159$ & $196 \pm 180$ & $256 \pm 219$ \\
\hline
\end{tabular}

Data are expressed as mean \pm SD or as number of patients.

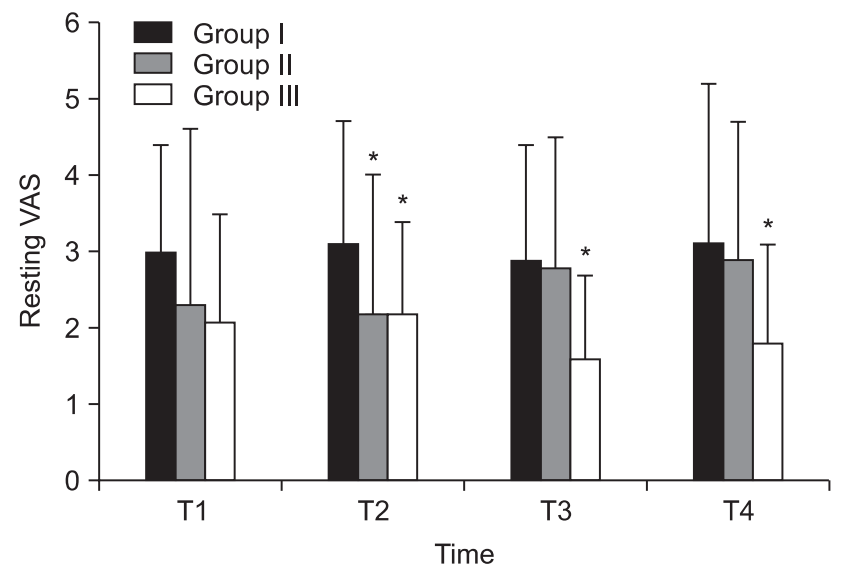

among the 3 groups with respect to parametric variables followed by student's t test. Categorical variables were analyzed using the chi-square test or Fisher's exact test, as appropriate. A $P$ value of $<0.05$ was considered significant.

\section{Results}

There were no significant differences in patient characteristics between groups (Table 1). The resting VAS was significantly lower in Group II at T2 compared to Group I. In Group III, the resting VAS was significantly lower at T2, T3, and T4 than in Group I. The effort VAS was significantly lower in Group III than in Group I at T3 and T4 (Fig. 1).

Postoperative rescue analgesic requirements and adverse effects are shown in Table 2. In the PACU, fentanyl was given in 11 patients in Group I, 4 in Group II, and 7 in Group III and there were no significant differences in the total amount of

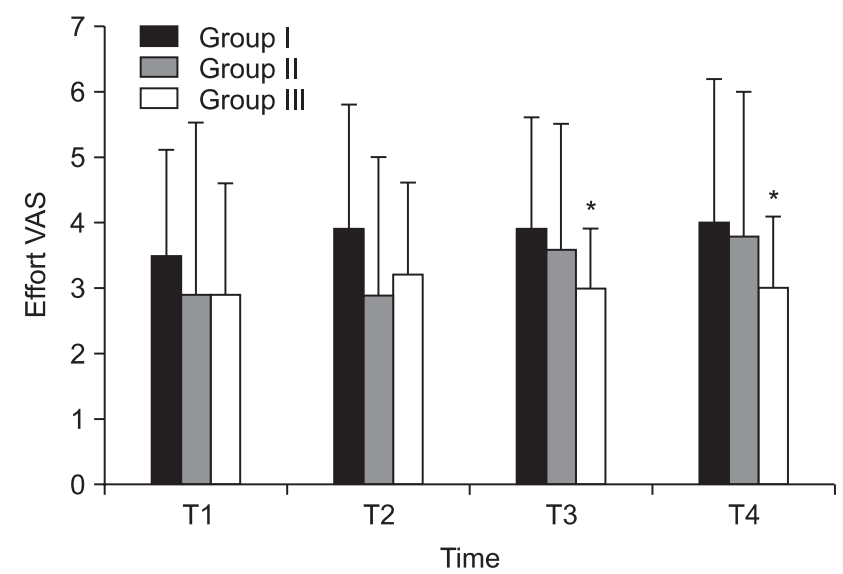

Fig. 1. Resting and effort visual analogue scale (VAS). T1: $5 \mathrm{~min}$ after arrival in post-anesthetic care unit, T2: discharge time from the postanesthetic care unit, T3: $24 \mathrm{~h}$ after the operation, T4: $48 \mathrm{~h}$ after the operation. ${ }^{*} \mathrm{P}<0.05$ vs. Group I.

Table 2. Postoperative Rescue Analgesic Requirement and Adverse Effects

\begin{tabular}{|c|c|c|c|c|}
\hline & $\begin{array}{l}\text { Group I } \\
(\mathrm{n}=30)\end{array}$ & $\begin{array}{l}\text { Group II } \\
(\mathrm{n}=30)\end{array}$ & $\begin{array}{c}\text { Group III } \\
(\mathrm{n}=30)\end{array}$ & P value \\
\hline \multicolumn{5}{|l|}{ Rescue analgesic requirements } \\
\hline Fentanyl in PACU (n) & 11 & 4 & 7 & 0.108 \\
\hline Postoperative 24 h (n) & 21 & $8^{*}$ & $8^{*}$ & $<0.001$ \\
\hline Postoperative $48 \mathrm{~h}(\mathrm{n})$ & 14 & 17 & 19 & 0.444 \\
\hline \multicolumn{5}{|l|}{ Total amount of rescue analgesics } \\
\hline Fentanyl in PACU (ug) & $18 \pm 25$ & $10 \pm 24$ & $15 \pm 23$ & 0.358 \\
\hline Meperidine 24 h (mg) & $42 \pm 40$ & $13 \pm 30 *$ & $14 \pm 25^{*}$ & 0.001 \\
\hline Meperidine 48 h (mg) & $23 \pm 31$ & $23 \pm 27$ & $21 \pm 19$ & 0.923 \\
\hline Time to $1^{\text {st }}$ rescue analgesics ( $\mathrm{hr}$ ) & $20 \pm 19$ & $30 \pm 15^{*}$ & $32 \pm 15^{*}$ & 0.015 \\
\hline \multicolumn{5}{|l|}{ Adverse effect } \\
\hline PONV & 0 & 2 & 0 & 0.129 \\
\hline Somnolence & 1 & 0 & 0 & 0.370 \\
\hline Pruritus & 1 & 1 & $6^{*}$ & 0.032 \\
\hline
\end{tabular}

Data are expressed as mean \pm SD or as number of patients (\%). PONV: postoperative nausea and vomiting. *P $<0.05$ vs. Group I. 
rescue fentanyl $(\mathrm{P}=0.358)$. The total requirements of rescue meperidine were significantly less in Groups II and III as compared to Group I at postoperative $24 \mathrm{~h}(\mathrm{P}=0.001)$ but, there were no significant differences at postoperative $48 \mathrm{~h}(\mathrm{P}=0.923)$. No significant differences were found in the incidence of nausea and vomiting between the groups. The frequency of pruritus was higher in Group III compared to Groups I and II (Table 2). No one showed peripheral oxygen desaturation $\left(\mathrm{SpO}_{2}<90 \%\right)$ throughout the study period.

\section{Discussion}

In patients undergoing gastrectomy, high thoracic epidural catheterization is commonly performed to provide continuous postoperative pain control. In spite of continuous epidural pain control, some patients frequently request additional analgesics. In our study, rescue analgesics were required in $8.9 \%$ of patients within 5 minutes of arrival in the PACU, in $15.6 \%$ by 30 minutes, in $41 \%$ within $24 \mathrm{~h}$ and in $55.6 \%$ by postoperative hour 48 .

Epidural steroid injection is a common modality for treatment of chronic pain. Dexamethasone has been demonstrated to reduce lumbar epidural puncture-induced backache [4], postoperative pain, and morphine consumption [5]. We conducted this study to assess the effects of epidurally administered dexamethasone on postoperative analgesia after major abdominal surgery. Although the underlying mechanism(s) of epidural steroid and local anesthetics are still not well understood, it is considered that the neural blockade alters or interrupts nociceptive input, reflex mechanisms of the afferent fibers, self-sustaining neuronal activity and the pattern of central neuronal activities [6]. In addition, steroids reduce inflammation by inhibiting either the synthesis or release of a several pro-inflammatory mediators and by causing a reversible local anesthetic effect. Epidural dexamethasone administration has been shown to reduce postoperative analgesic requirements in dental, laparoscopic and breast surgeries [7-10].

However, there have been no studies investigating the effect of epidural dexamethasone treatment on pain after major abdominal surgery. The major finding of this study was that 5 mg of epidurally administered dexamethasone was effective in reducing the degree of pain and rescue analgesic requirements after radical subtotal gastrectomy during the early postoperative period.

Acute noxious stimulation of peripheral tissues leads to sensitization of dorsal horn neurons of the spinal cord by the release of excitatory amino acids such as glutamate and aspartate. These amino acids activate N-methyl-D-aspartate receptors resulting in calcium ion influx. As a result, increased intracellular calcium activates phospholipase $\mathrm{A}_{2}$ which converts membrane phospholipids to arachidonic acid. Simultaneously, there is up-regulation of the expression of cyclo-oxygenase 2 in the spinal cord, leading to prostaglandin $\mathrm{E}_{2}$ synthesis, which results in a hyperalgesic state [1,3]. Epidural dexamethasone administration may influence intraspinal prostaglandin synthesis by inhibiting phospholipase $\mathrm{A}_{2}$ and the expression of cyclo-oxygenase 2 [1]. Steroids also suppress transmission in thin unmyelinated C-fibers and bind directly to the intracellular glucocorticoid receptor [11].

The exact onset time of dexamethasone is unclear and the appropriate timing for administration is still controversial. Some have reported preoperative administration of epidural dexamethasone reduces postoperative pain and analgesic requirements $[5,12]$. Tissue injured during surgery acts as an acute noxious stimulation to other tissues. Thus, it leads to activation of phospholipase $A_{2}$ and the expression of cyclooxygenase 2 in the spinal cord, resulting in prostaglandin synthesis and induction of a hyperalgesic state [3]. Preoperative administration of steroids may reduce these reactions and improve analgesia [9]. In a recent meta-analysis, preoperative or postoperative epidural steroid treatment decreased pain and shortened the length of hospital stays after lumbar spinal surgery [13]. In our study, the preoperative dexamethasone group (Group II) had a low resting VAS after $30 \mathrm{~min}$ in the PACU and the postoperative dexamethasone group (Group III) had a low resting VAS after $30 \mathrm{~min}$ of PACU as well as 24 and $48 \mathrm{~h}$ postoperatively. Effort VAS for Group II was also significantly higher than in Group III and there was no difference when compared to Group I.

Because we could not rule out the possible bias in pain assessment, we evaluated the number of rescue analgesic requirements and total amount of rescue opioid used. The time to the first rescue analgesic requirement was longer and the total amount of rescue meperidine used during the first 24 $\mathrm{h}$ of the postoperative period was less in the dexamethasonetreated groups (Group II and III) than in the group not receiving dexamethasone (Group I). Although we could not conclude the proper time to administer epidural dexamethasone because pain is very subjective and affected by many factors, epidural dexamethasone administration may alleviate the pain after major abdominal surgery.

The incidence of postoperative nausea and vomiting as well as somnolence was not significantly different between groups. However, the frequency of an itching sensation was higher in Group III. Ironically, i.v. dexamethasone-induced perineal pruritus has been described in patients with chemotherapy and acute head injury in an attempt to reduce intracranial pressure and oral surgery [14-16]. This adverse effect can be prevented by slowly giving diluted dexamethasone [17]. Also, because intrathecally or epidurally administered opioid-induced pruritus is not associated with histamine release, $\mathrm{H}_{1}$ blockers 
have little effect on the development of pruritus after opioid administration $[18,19]$. In our study, no one showed perineal pruritus and all symptoms of pruritus were relieved by the administration of diphenhydramine.

In conclusion, the epidural administration of $5 \mathrm{mg}$ of dexamethasone can reduce the pain and rescue analgesic requirements $24 \mathrm{~h}$ after radical subtotal gastrectomy. Further study is required for determination of the proper timing of dexamethasone administration.

\section{References}

1. Abram SE, Marsala M, Yaksh TL. Analgesic and neurotoxic effects of intrathecal corticosteroids in rats. Anesthesiology 1994; 81: 1198205.

2. Yao XL, Cowan MJ, Gladwin MT, Lawrence MM, Angus CW, Shelhamer JH. Dexamethasone alters arachidonate release from human epithelial cells by induction of p11 protein synthesis and inhibition of phospholipase A2 activity. J Biol Chem 1999; 274: 17202-8.

3. Ebersberger A, Grubb BD, Willingale HL, Gardiner NJ, Nebe J, Schaible HG. The intraspinal release of prostaglandin E2 in a model of acute arthritis is accompanied by an up-regulation of cyclooxygenase-2 in the spinal cord. Neuroscience 1999; 93: 775-81.

4. Wang YL, Tan PP, Yang CH, Tsai SC, Chung HS. Epidural dexamethasone reduces the incidence of backache after lumbar epidural anesthesia. Anesth Analg 1997; 84: 376-8.

5. Thomas S, Beevi S. Epidural dexamethasone reduces postoperative pain and analgesic requirements. Can J Anaesth 2006; 53: 899-905.

6. Abdi S, Datta S, Trescot AM, Schultz DM, Adlaka R, Atluri SL, et al. Epidural steroids in the management of chronic spinal pain: a systematic review. Pain Physician 2007; 10: 185-212.

7. Hval K, Thagaard KS, Schlichting E, Raeder J. The prolonged postoperative analgesic effect when dexamethasone is added to a nonsteroidal antiinflammatory drug (rofecoxib) before breast surgery. Anesth Analg 2007; 105: 481-6.

8. Numazaki M, Fujii Y. Reduction of postoperative emetic episodes and analgesic requirements with dexamethasone in patients scheduled for dental surgery. J Clin Anesth 2005; 17: 182-6.

9. Bisgaard T, Klarskov B, Kehlet H, Rosenberg J. Preoperative dexamethasone improves surgical outcome after laparoscopic cholecystectomy: a randomized double-blind placebo-controlled trial. Ann Surg 2003; 238: 651-60.

10. Fujii Y, Nakayama M. Reduction of postoperative nausea and vomiting and analgesic requirement with dexamethasone in women undergoing general anesthesia for mastectomy. Breast J 2007; 13: 564-7.

11. Johansson A, Hao J, Sjölund B. Local corticosteroid application blocks transmission in normal nociceptive C-fibres. Acta Anaesthesiol Scand 1990; 34: 335-8.

12. Sistla S, Rajesh R, Sadasivan J, Kundra P, Sistla S. Does singledose preoperative dexamethasone minimize stress response and improve recovery after laparoscopic cholecystectomy? Surg Laparosc Endosc Percutan Tech 2009; 19: 506-10.

13. Ranguis SC, Li D, Webster AC. Perioperative epidural steroids for lumbar spine surgery in degenerative spinal disease. A review. J Neurosurg Spine 2010; 13: 745-57.

14. Thomas VL. More on dexamethasone-induced perineal irritation. N Engl J Med 1986; 314: 1643-4.

15. Klygis LM. Dexamethasone-induced perineal irritation in head injury. Am J Emerg Med 1992; 10: 268.

16. Andrews D, Grunau VJ. An uncommon adverse effect following bolus administration of intravenous dexamethasone. J Can Dent Assoc 1986; 52: 309-11.

17. Taleb N, Geahchan N, Ghosn M, Brihi E, Sacre P. Vulvar pruritus after high-dose dexamethasone. Eur J Cancer Clin Oncol 1988; 24: 495.

18. Szarvas S, Harmon D, Murphy D. Neuraxial opioid-induced pruritus: a review. J Clin Anesth 2003; 15: 234-9.

19. Kam PC, Tan KH. Pruritus--itching for a cause and relief? Anaesthesia 1996; 51: 1133-8. 